\title{
Promoting Spatial Thinking and Learning with Mobile Field Trips and eGeo-Riddles
}

\author{
Elisa MICHEL and Angela HOF \\ Geography Department, Ruhr-University Bochum/Germany·elisa.michel@rub.de \\ This contribution was double-blind reviewed as full paper.
}

\begin{abstract}
This paper presents a concept for an innovative teaching and learning project which combines core topics from Physical Geography with adventure and media pedagogy by providing settings for multimedia education in the field. Locations are used as learning spaces and spatial information is integrated in a direct context. The objective of the project is to take e-learning to the field by expanding it for mobile, flexible, location-based learning processes. Learning resources and outdoor activities are combined to get original nature experiences with its varied spatial and temporal dimensions. Mobile tagging, QuickResponse Codes (QR-Codes) and mobile applications are used to access the project results with mobile devices in the field. The benefits and challenges for embedding mobile devices in the curriculum are discussed by presenting a practical example and implementation of mobile field trips and eGeo-Riddles. Target audience of the final products are Bachelor students. The focus of the project is on the supply of teaching and learning content to support the holistic understanding of spatial concepts and to create curiosity and awareness for environmental processes.
\end{abstract}

\section{Introduction: Structural and Formal Background}

Various activities of our life are affected by spatial factors. The ability to recognize and combine features and to interpret and visualize spatial data is fundamental to content understanding and problem solving. Spatial thinking describes not only the understanding of specialized spatial processes but it includes elements of spatial concepts, tools and methods for spatial representation, as well as the process of spatial reasoning (see Fig. 1). These links among space, representation, and reasoning give the process of spatial thinking its power of versatility and applicability. Within the three related terms spatial structures can be extracted, spatial transformations can be performed, and functional interferences can be analyzed and presented. Thus, the concept of spatial thinking represents a vehicle for structuring problems, finding answers, and expressing solutions (cf. NRC 2006).

Geography is a spatial science and spatial thinking as well as interdisciplinary analysis are core competences of geographers. Location-based learning has major importance for spatial learning processes, because it represents a particular component for understanding ecological and environmental processes on-site (cf. CHATTERJEA et al. 2008). Physical geographers 
traditionally incorporate components of fieldwork and location-based learning into the curriculum and they can be seen as pioneers of active learning (DAY 2012).

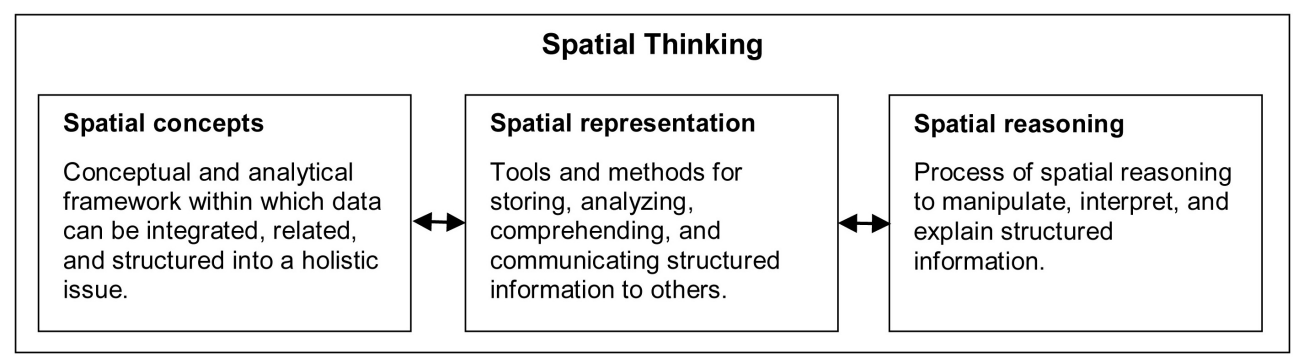

Fig. 1: Spatial Thinking, its dimensions and related terms. Own figure. Definitions of terminology according to NRC 2006.

In spite of the importance of location-based learning and the requirement of students for more practical examples, the quantity of days for field trips and practical fieldwork were reduced within the Bachelor's Geography curriculum. Thus, due to the Bologna reform, institutions are challenged to provide this special teaching method with new teaching models. This deficit of field trips offered by the institution may coincide with rising student numbers, like for example in North Rhine-Westphalia, where this situation is a result of the modification of the school system. On the basis of international standards, a law for reducing the school years from 13 to 12 years was passed in 2005. Because of that, two cohorts (called G8 and G9) arrive in the upper school level in the years 2010/2011, and graduate with the general higher education entrance qualification in 2013. According to the current forecast of the North Rhine-Westphalian Ministry of Education, the demand for university places will increase significantly. Although the school time reduction only affects secondary schools, an increase of 10,000 to 12,000 freshmen is expected in 2013 (MSW 2006 - 2012). This increased demand for university places in combination with economic pressures poses a lot of challenges for the universities in North RhineWestphalia.

One of the strategies advocated by the people in charge is to resort to new or alternative teaching models with multimedia elements to serve the quality of education. Thus, several e-learning courses on the internet as well as a wide range of GPS-based learning and adventure opportunities have been established in recent years. At the same time, mobile nature trails and programs, like Audio-Guides or City Apps, are enjoying a growing popularity, especially in the general public. In this context, Geocaching is a major and persistent trend with currently more than 27,000 active Geocaches (DEUTSCHE WANDERJUGEND 2013). However, within the academic teaching community in Geography, these new teaching and learning elements and models, and the application of mobile devices are discussed controversially. While some authors express oneself rather skeptical towards such teaching methods and call the novelty of the approaches into question (e.g. DAY 2012), other authors are convinced of the opportunities for their successful integration for teaching and learning (e.g. MICHEL 2013, ZECHA 2012). A detailed overview of the mobile, locationbased learning tools and approaches and their benefits and challenges are presented in LUDE et al. (2013). Against these structural and formal backgrounds, the motivation of the project is the expansion of the use of mobile devices for e-learning in the field. 


\section{Conceptual Design and Project Idea}

The eGeo-Riddle project picks up the trend of mobile and spatially-enabled devices, the popularity of nature trails and environmental education and combines adventure and media pedagogy with multimedia environmental education for Geography students in the field.

The project aims to jazz up a formal lecture in Physical Geography by providing mobile field trips for independent and flexible learning processes in the field. The content created for this purpose links real places in the surroundings of the university to lecture content and geographic topics intelligently. Spatial information and field methods are integrated into a direct context to acquire knowledge independently and flexibly in the field.

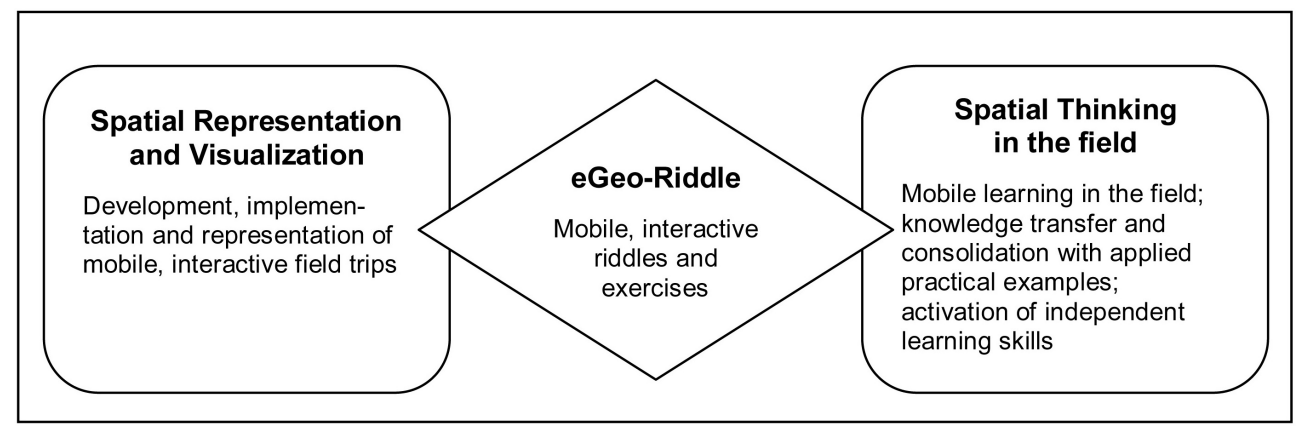

Fig. 2: Conceptual design and project idea of mobile field trips and eGeo-Riddles

In contrast to nature trails and according to the Chinese proverb: "Tell me, and I'll forget. Show me, and I may remember. Involve me, and I'll understand", the current project aims at an active engagement and participation of the students. In addition to video-podcasts with geographic information about the landscape, users of this project will be animated to actively collaborate and experience a range of things in the field through active touching, feeling, comparing, testing etc. Spatial information and field methods of Landscape Ecology and Biogeography are worked out and embedded in a direct context for locationbased learning.

The project idea is the creation and implementation of mobile field trips within spatial representation and visualization tools to improve spatial thinking in the field (see Fig. 2). Learning resources and outdoor activities are combined with an active use of Geoinformation and GI-technology on the premise that application and development of these contents and tools in Geography education at all levels offers a lot of opportunities for Geography and the discipline's public representation (GOODCHILD \& JANELLE 2010). Besides this, the concept introduces a game-based learning element which we call eGeoRiddle. Basically, the eGeo-Riddle is a hybrid that includes mobile, interactive exercises wrapped in a riddle-like assignment that has to be worked on. 


\subsection{Didactic concept and learning objectives}

The content for learning with mobile field trips and eGeo-Riddles is prepared for Bachelor of Science Geography students and can be optimally integrated in several existing courses as an additional learning offer. The project picks up the self-learning concept of the successful internet platform webgeo.de (IPG 2001-2009) and expands it with mobile applications and location-based exercises.

The objectives of the project are related to the improvement of the methodological and professional Geography skills of students. The focus is on direct nature experience and education in the field to support spatial thinking and to compensate the deficit of field trips within the Bachelor's Geography program. The main task is the conceptual work and implementation of practical e-learning services in the field that invite and encourage students to occupy themselves intensively with a specific range of topics. Disciplinary knowledge is processed and communicated with specific background information, small riddles, and experiments about the location and the environment. The focus of the learning experience that is to be created is not on the examination of factual knowledge but on the application of geographical knowledge for spatial questions and phenomena.

A main focus is on the holistic understanding of causal connections and interrelatedness in the natural and material environment. According to this, the main questions to be answered are:

1. how can we integrate mobile field trips in the learning experience to support spatial thinking?

2. which distinctive characteristics of a place can be presented, in which ways, within elearning services in the field?

3. and how can we motivate and actively engage students for mobile field trips?

\section{Design and Technical Implementation of Mobile Field Trips and eGeo-Riddles}

The mobile field trips combine classical e-learning tools and practical field work with multimedia elements and mobile game-based applications. A main tool for the mobile field trips is a Learning Management System (LMS). The platform, accessible to all Geography students at our University, is linked to our e-learning System including interactive applications. It is used as a representation and communication tool for independent learning activities. The combination of learning resources and activities to promote spatial thinking and learning is presented in Figure 3.

On this LMS students get all information for the particular field trips like time requirement and recommended reading, a brief summary of each field trips and related previous knowledge as well as the required equipment (e.g. GPS, mobile device with internet connectivity, paper pad, compass etc.).

For the performance of the mobile field trips users have to own or borrow an internetenabled mobile device (e.g. smartphone or tablet) with an installed QR-Code scanner. Be- 
cause this shouldn't represent an obstacle for the students, all required technical equipment as well as mobile devices can be borrowed from the Department.

In a first learning unit the spatial characteristics and structures of the study area are briefly presented. Within this introduction session students are prepared for the following mobile field trips and its exercises.

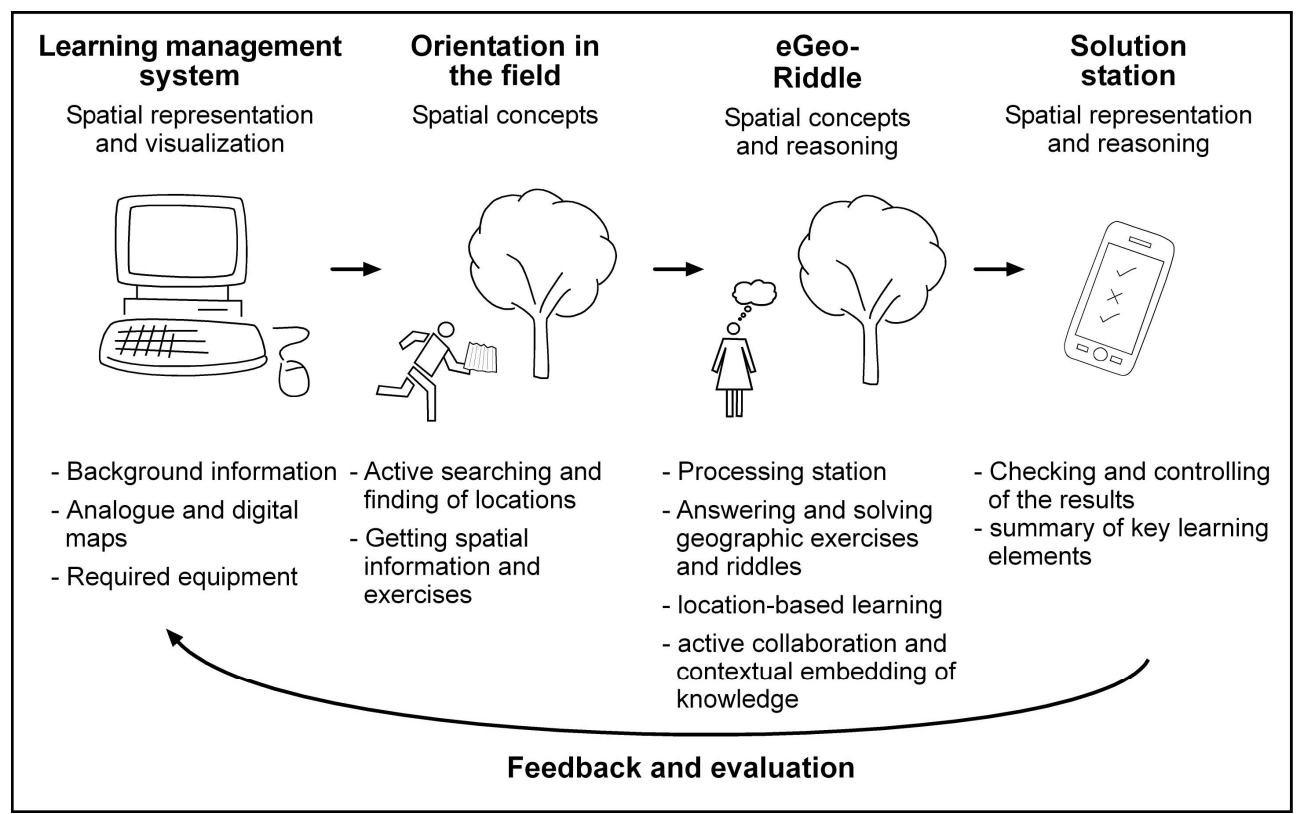

Fig. 3: Combination of learning resources and activities to promote spatial thinking and learning

The particular locations are to be found through analogue and digital maps, possibly with route suggestions with or without concrete coordinates, which can be visited in any order. By this active searching and finding of the field trip locations students train spatial orienteering. The individual locations are geotagged with small hidden labels with QuickResponse Codes (QR-Codes), which contain encrypted information about the eGeo-Riddle. QR-Codes are comparable to bar codes on packaging. They represent two-dimensional codes to encrypt information up to 4296 signs. For decrypting, the QR-Code has to be scanned with the Smartphone or other mobile devices and decoded with a special application. This technology offers the possibility to get tangible information about a special location, which can be directly augmented by mobile applications. By accessing learning content with mobile devices students engage directly with the environment and receive further information about the surrounding space. This computer-based extension of reality is also called augmented reality.

The respective QR-codes link to the video portal of our university, where the specific learning contents are delivered via video-Podcasts and multimedia elements. After a short introduction of a specific range of topics, the users have to answer and solve geographic 
exercises and riddles. This eGeo-Riddle is an integral game-based element of the mobile field trips to achieve an interactive learning experience. Similar to Multi- and PuzzleCaches, a solution and summary of the exercise is only given after processing and solving the eGeo-Riddle. Thus, the answer gives a direct hint for the solution station, where students can actively check and control their own results. On this solution/evaluation station, key learning elements are briefly summarized within examples and further information. All information of the mobile field trips is only accessible locally.

Additionally, the LMS comprises an interactive glossary, where important terms and concepts can be looked up. To actively control and check the acquired knowledge of the mobile field trips, the LMS includes a final Multi-Cache which is directly linked to the learning units and aspects of the various mobile field trips and eGeo-Riddles. For a further students incentive, the final Multi-Cache ends at a special view point with concrete hints for the exams.

Another important feature of the LMS is the evaluation and feedback tool that can be used as an interactive element to exchange experiences and to give and receive feedback. Furthermore, the concept as well as the results are presented and discussed in the colloquium of the working group for Landscape Ecology and Biogeography with students, lectures and external experts. In this way, the developer's team gets direct feedback with constructive criticism and suggestions for the practical implementation. This targeted feedback and evaluation aims to enhance the mobile field trips qualitatively.

\section{Practical Example and Integration of Mobile Field Trips and eGeo-Riddles into the Curriculum}

The general model of each mobile field trip is a structure of three learning units including a multimedia introduction with background information for a knowledge transfer, the eGeoRiddle with interactive exercises and riddles in the field as well as the solution and evaluation station for post processing and knowledge consolidation (see Fig. 4). Lectures on Biogeography are shifted into the outdoors and are complemented with practical examples in the field to get original representations of varied spatial and temporal dimensions of environmental processes.

For getting an idea of mobile field trips and eGeo-Riddles, a complete activity model with practical examples and exercises for the implementation is explained in the following paragraphs. The example deals with the ecological significance of deadwood (Fig. 4). A multimedia introduction and practical examples with audio and video files are wrapped up to deliver a representation of deadwood types and structures directly in the field. Within the eGeo-Riddle activity and processing unit students have to apply and embed their expertise in a critical and analytical way. Thus, to promote spatial reasoning and interpretation students are invited to detect and map different deadwood types and structures in an interactive map. By going outside, making own observations and taking samples, students train the way of thinking with and about space and they acquire a tangible imagination of spatial characteristics and differences. Besides this active collaborating and experiencing in the field, students have to transfer the acquired knowledge for recognizing different deadwood habitats and deadwood species. They practice how to integrate and apply spatial knowledge in a direct context and they are learning by doing science in the field. For the 
learning effect this active collaboration and contextual embedding of knowledge is very important, because own nature experiences are gained and environmental conflicts and spatial characteristics can be better understood compared to the audio-visual presentation in the lecture hall alone (cf. WESTERA 2011; ZECHA 2012). Working towards a goal, the solution station is hidden behind a special deadwood structure, for example a woodpecker's hole. The location thereof is only disclosed after solving a particular eGeo-Riddle correctly. At this solution station different deadwood habitats are directly visible in their real-world spatial context. Thus, in terms of augmented reality the real environment is combined with virtual contents.

Within this goal- and reward-directed practical learning experience students get a direct feedback of their own acting and experiencing. Thus, by integrating game and adventure based elements in the learning process, students get an engaging learning experience, while at the same time important skills, such as collaboration, creativity, and critical thinking are improved (cf. Johnson et al 2012).

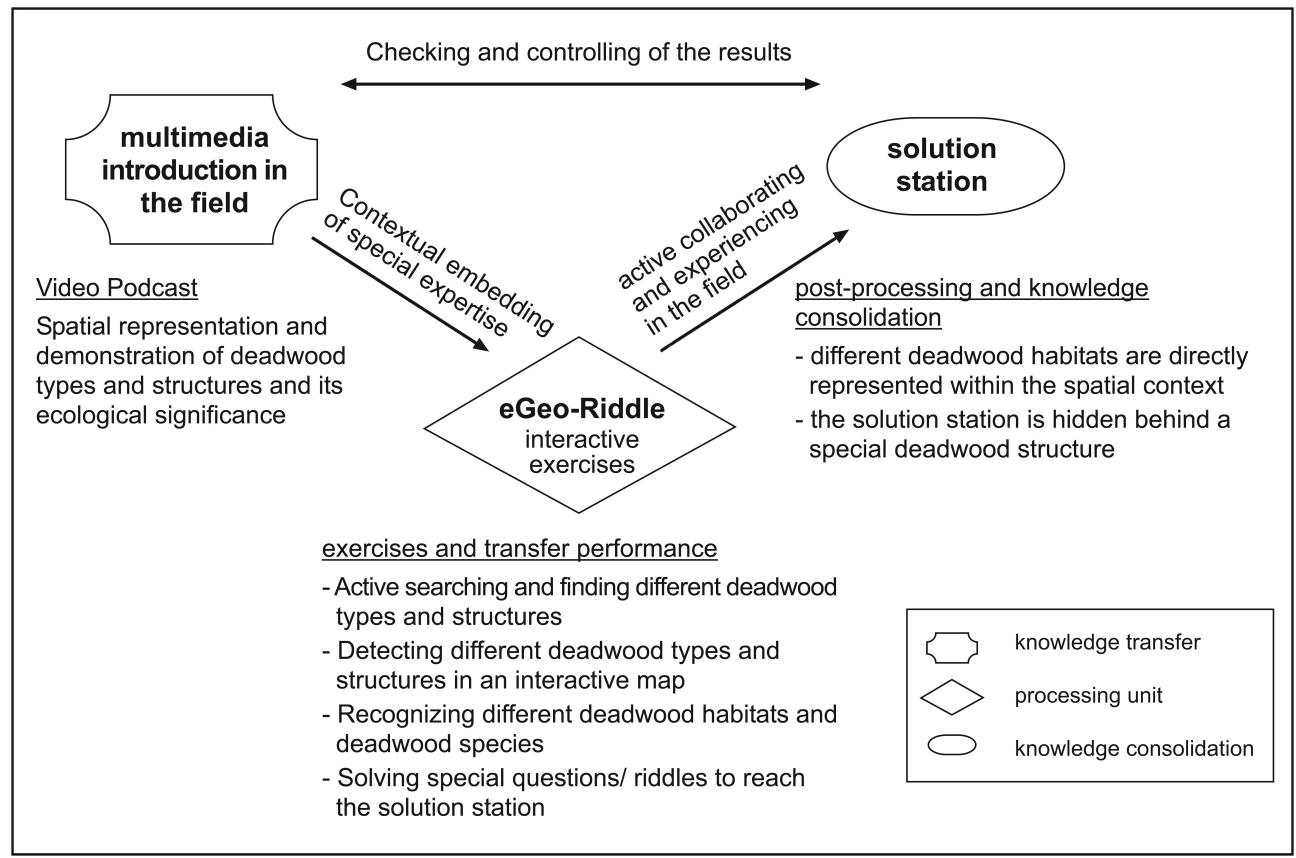

Fig. 4: Model of a mobile field trip and eGeo-Riddle for a practical example in Biogeography

The practical example of a mobile field trip and eGeo-Riddle shows that lectures and tutorials can be jazzed up and modified didactically by means of integration of new teaching methods, because it provides a varied learning and teaching environment. With the content provided on the LMS and the installed QR-Codes students can acquire spatial knowledge and skills independently and flexibly in the field with mobile devices. Solving the eGeo-Riddles students learn not only the facts, but also the application and acquiring of 
special geographic skills and knowledge in true to life situations. In this way they learn to transfer learning outcomes to the real world environment.

To motivate and engage the students, the learning opportunity of the mobile field trips will be presented at the beginning of the Geography study in all lectures and seminars that provide the opportunity to learn with mobile field trips and eGeo-Riddles. Furthermore, there will be orientation sessions for the introduction to reduce inhibitions or obstacles to uptake and implementation and to support self-learning skills. Due to the orientation session and the practical introduction, on the one hand, a great part of students should be reached. On the other hand, the curiosity for the independent use of the platform should be created. Thus, the self-learning part rises gradually.

The concept of mobile field trips and eGeo-Riddles is transferable for all subjects with a spatial relation and can be optimally integrated into several courses of the Bachelor's Geography program. In a first step it is planned to firmly integrate the mobile field trips into the existing course 'Introduction to Physical Geography'. This module is an obligatory lecture with tutorial courses for all Bachelor of Science Geography students in the first and second semester with 10 ECTS credit points, where fundamental topics of Geography are represented in a classical face-to face lecture and tutorials held by student assistants that focus on practical exercises to reiterate contents that were presented in the lectures. In the present form, this course concept has been established since more than four years and it is remarkably well supported and complemented by e-Learning content (tests, exercises, lecture material). This learning content is extended by the mobile field trips and eGeoRiddles to integrate mobile, flexible, location-based learning experiences in the curriculum.

\section{Conclusion and Outlook}

The combination of mobile nature trails and lecture content offers a great potential for mobile, flexible, location-based learning processes. Hence, mobile devices present great benefits for spatial thinking and learning in the field. The e-learning content created by the project represents a supplement to the traditional face-to-face learning models with a high relevance for teaching, learning, and creative inquiry. Students can interact directly with the environment and they are encouraged to think and act spatially. Indeed, this new learning method and format cannot replace the established one but it can be seen as a useful supplement of active and competence-oriented learning. Furthermore, it is an effective possibility to compensate the deficit of field trips and field work within the Bachelor's Geography study. For the learning processes, mobile devices represent an important supporting and representation tool including a lot of opportunities and varieties for describing, explaining, and communicating spatial characteristics. Because of the ongoing trend and the great acceptance of such technical equipment, their use within learning context should not be seen as a problem, but rather as an opportunity, especially in Geography. However, for an effective learning environment these technologies should never be the focus, but used as media and supporting tool to convey disciplinary knowledge.

The spatial perspective of the mobile field trips includes reading and understanding maps for navigation, the arrangement of spatial information, the recognizing and combining of 
features and content up to the level of data interpretation in the field. In this way, explicit linkages between the three elements of spatial thinking are built.

The paper presents a conceptual contribution for mobile field trips and eGeo-Riddles. The technical implementation and evaluation is planned for the summer term 2013. Regarding the long-term objectives of the project, that is, getting an adequate e-learning service in the field, it is planned to continue and expand the additional field trips by subsequent projects or even by a course concept that involves students in the creative process of developing contents and eGeo-Riddles.

Limits and challenges of the project are the need for permanent care and maintenance of the mobile field trips and the continuation of the services on the internet and the LMS platform. The main technical and didactic challenges for the mobile field trips are the limited data volume and the amount of information, which has to be presented in a short and useroriented way, optimized for mobile devices. Amongst other factors, the seasonal variations of landscape structures represent conceptual challenges for the implementation.

On the whole, the project concept represents interdisciplinary teaching, learning, and creative inquiry learning opportunities for promoting spatial thinking and learning. The concept is transferable to all courses with a spatial content and can be used as an optimal supplement for traditional teaching methods.

\section{Acknowledgements}

We are grateful for financial support from the Rectorate of Ruhr University Bochum, Germany, granted in 2012-2013, for the learning project 'Update geographischer Exkursionen mit Geocaching und E-Learning im Gelände'.

\section{References}

Chatterjea, K., Chang, C-H., Lim, E-P., Zhang, J., Theng, Y-L. \& Go, D. H-L. (2008), Supporting Holistic Understanding of Geographical Problems: Fieldwork and G-Portal. International Research in Geographical and Environmental Education, 17 (4), 330-343.

DAY, T. (2012), Undergraduate teaching and learning in physical geography. Progress in Physical Geography, 1-28.

Deutsche WANDERJUGEND e. V. (Ed.) (2013), Geocaching.de. Statistiken. http://cms.geocaching.skylink.de/index.php?id=9 (24.1.2013).

GoodCHILD, M. F. \& JANELlE, D. G. (2010), Toward critical spatial thinking in social sciences and humanities. GeoJournal, 75 (1), 3-13.

IPG - Institut für Physische Geographie (Eds.) (2001-2009), WEBGEO. Albert-LudwigsUniversität Freiburg. http://www.webgeo.de/home/ (22.01.2013).

JoHnson, L., ADAMS, S. \& CuMMINS, M. (Eds.) (2012), NMC Horizon Report: 2012 Higher Education Edition. Austin, Texas, The New Media Consortium.

Lude, A.. SchaAl, S.. Bullinger, M. \& BlecK, S. (Eds.) (2013), Mobiles ortsbezogenes Lernen in der Umweltbildung und Bildung für nachhaltige Entwicklung. Hohengehren. 
Michel, U. (2013), Smartphone und Co - Einsatz digitaler und mobiler Technologien in Bildungsangebote. In: Lude, A., SchaAl, S., Bullinger, M. \& Bleck, S. (Eds.) (2013), Mobiles ortsbezogenes Lernen in der Umweltbildung und Bildung für nachhaltige Entwicklung. Hohengehren, 13-17.

MSW - MINISTERIUM FÜR SCHULE UND WEITERBILDUNG DES LANDES NORDRHEINWESTFAlEN (2006-2012), SCHULMINISTRERIUM.NRW.DE. Das Bildungsportal. Doppelter Abiturjahrgang 2012/2013.

http://www.schulministerium.nrw.de/BP/Schulsystem/Schulformen/Gymnasium/Doppel jahrgang1/index.html (07.01.2013).

NRC - NATIONAL RESEARCH COUNCIL (Ed.) (2006), Learning to think spatially. Washington DC, National Academic Press.

WesterA, W. (2011), On the Changing Nature of Learning Context: Anticipating the Virtual Extensions of the World. Educational Technology \& Society, 14 (2), 201-212.

ZECHA, S. (2012), Geocaching, a tool to support environmental education!? - An explorative study. Educational Research EJournal, 1 (2), 177-188. doi:10.5838/erej.1.2. 